\title{
Classification of four ovine breeds of southern peninsular zone of India: Morphometric study using classical discriminant function analysis
}

\author{
Dinesh Kumar Yadav ${ }^{1 *}$, Anand Jain ${ }^{1}$, Viswanath Sheshagirirao Kulkarni², Mandera Giriyappa Govindaiah³, \\ Thimmappa Aswathnarayan ${ }^{4}$ and Devinder Kumar Sadana ${ }^{1}$
}

\begin{abstract}
Six morphometric traits (height at withers, body length, chest girth, ear length, tail length and body weight) were analyzed to characterize from a breed point of view 1981 sheep from four ovine breeds (Bellary, Kenguri, Hassan and Mandya) of southern peninsular zone of India. Discriminant Function Analysis was used to distinguish between four breeds by morphometric traits. The population variability showed Kenguri ewes were the largest and heaviest followed by Bellary, Hassan and Mandya whereas Kenguri rams were followed by Bellary, Mandya and Hassan. Overall sexual dimorphism (m/f) was 1.13, with Kenguri males being $47 \%$ heavier than females. The coefficient of variation of all traits in four breeds ranged from $4.06 \%$ to $30.28 \%$. The flocks and age effects showed a high heterogeneity among females of different flocks. Height at withers was most discriminating trait in separating the four sheep breeds. The Mahalanobis distance of the morphological traits between Kenguri and Mandya sheep was most while the least differentiation was observed between Kenguri and Bellary sheep. Nearest neighbour discriminant analysis showed that most Kenguri sheep were classified into their source population followed by Mandya. However, varied percentages of misclassification between different breeds were observed showing the level of genetic exchange that has taken place between the breeds overtime. UPGMA based dendrogram showed formation of two separate groups; Mandya and Hassan clustered together while Bellary and Kenguri formed other group.
\end{abstract}

Keywords: Bellary, Discriminant analysis, Morphometric traits, Hassan, Kenguri, Mandya, Sheep

\section{Introduction}

India is a rich source of diverse ovine germplasm with 74 million sheep which is $6.8 \%$ of world sheep population (FAOSTAT 2010). According to the FAO (2000), there are 60 sheep breeds in India including well-recognized, lesser known and some wild species. Karnataka, an Indian state lying in its Southern peninsular agro-ecological zone, has sheep as a socio-economically important livestock reared primarily as a source of mutton in rural areas. The state enjoys tropical monsoon type climate and hosts four well adapted sheep breeds viz. Bellary, Kenguri, Hassan and Mandya. Mandya breed is perhaps the best mutton breed of the country as far as conformation is concerned, al-

\footnotetext{
* Correspondence: dkyadav66@gmail.com

'National Bureau of Animal Genetic Resources, G. T. Road, Baldi By-Pass, Karnal 132 001, Haryana, India

Full list of author information is available at the end of the article
}

though body weights, weight gains, feed conversion efficiency and carcass yield are not very superior to most other breeds (Acharya 1982).

Contributions to characterization of local domestic animal populations are of major importance as the breed is the operation unit for the assessment of livestock diversity all over the world (Simon 1999; Duchev and Groeneveld 2006). While Lanari et al. (2003) emphasized characterization of livestock breeds as the first approach to a sustainable use of animal genetic resources; Gizaw et al. (2007) highlighted identification of populations based on morphological descriptors as the first phase of characterization. Despite the fact that, in general, no breed classification should rely exclusively on biometric data, these play a proxy or complementary role in the description of a breed (Parés i Casanova 2009). Attempts for phenotypic characterization and classification of Indian sheep breeds 
have not only been limited to single breed/population but also to the use of univariate analysis methods (Bohra et al. 1993; Sahana et al. 2001; Kumar et al. 2006; Singh et al. 2007; Jain et al. 2009; Yadav et al. 2009, 2011, 2012). The current trend in livestock classification using multivariate statistical tools (Herrera, 1996; Zaitoun et al. 2005; Dossa et al. 2007; Traoré et al. 2008; Yakubu et al. 2011) has not yet found place in the morphometric differentiation of Indian sheep breeds. In all these cases, the classical discriminant function analysis method was found to be relatively efficient and allowed differences between breeds and subpopulations to be detected, as well as the relative distance between them to be assessed. Further, the variables with greatest power to differentiate were identified enabling them to be weighted accordingly. Our study, attempts to investigate the above aspects in four Indian sheep breeds based on morphometric traits using multivariate analysis methods.

\section{Materials and methods}

\section{Study area and agro-climatic conditions}

Indian sheep breeds are distributed in the four major agroecological regions: the Northern temperate, North-western arid and semi-arid, Southern peninsular and Eastern (Acharya 1982; Bhatia and Arora 2005). The present study was conducted in the Karnataka state located between latitudes $11^{\circ} 30^{\prime} \mathrm{N}$ and $18^{\circ} 23^{\prime} \mathrm{N}$ and longitudes $74^{\circ} 05^{\prime} \mathrm{E}$ and $78^{\circ}$ $35^{\prime} \mathrm{E}$ in the Sothern peninsular region of India. Karnataka is the third largest sheep rearing state of India with 9.5 million sheep population (BAHS 2010). The climate is tropicalmonsoon type with temperature reaching as high as $42^{\circ} \mathrm{C}$ in summers and as low as $12^{\circ} \mathrm{C}$ in winters. The breeding tract of Bellary and Kenguri breeds fall in Northern Dry Zone of the state, a drought prone area. Annual rainfall varies from $633-807 \mathrm{~mm}$ and temperature ranges from $18^{\circ} \mathrm{C}$ to $40^{\circ} \mathrm{C}$. The altitude ranges from $465-786$ meters above sea level. The soils are red sandy loam, red loam and shallow black. Major crops grown are sorghum (Sorghum bicolor), Groundnut (Arachis hypogea), Bajra (Pennisitum typhodes), oilseeds and pulses. The distribution areas of Hassan and Mandya sheep fall in Southern Transition Zone of Karnataka. The altitude varies from 150-250, 250-300 and 300-500 meters above sea level at different places. Annual rainfall ranges from $671-887 \mathrm{~mm}$. Majority of soils are red sandy loam but in some pockets red loams are also present. Crops grown in the area are sorghum (Sorghum bicolor), ragi (Eleusine coracana), maize (Zea mays), groundnut (Arachis hypogea), sugarcane (Saccharum officinarum), cotton (Cocos nucifera) and arecanut (Areca catechu).

\section{Management practices}

All sheep breeds under study were subjected to extensive management system with little or no supplementary feeding. The animals grazed during the day on crop stubbles and low grade forage on barren land and roadsides for 6-8 hours and walked a distance of about 5-20 kilometres. They were taken to water source two or three times a day. During lean period, only Mandya sheep were given supplementary feed like jowar (sorghum), wheat (Triticum), ragi (Eleusine coracana), horse gram (Macrotyloma uniflorum) husk, and leaves of acacia, peepal (Ficus religiosa) and neem (Azadirachta indica). Stall feeding of small flocks was a routine practice carried by Mandya sheep rearers but Bellay sheep rearers provided supplementary feeding to the breeding rams during breeding season only. Mandya and Kenguri sheep flocks were stationary. Most of the Hassan sheep flocks were stationary but some flocks migrated to the adjoining areas during the lean periods of March to June. Bellary sheep migrate to the southern parts of the state (up to 150-300 kilometres) during DecemberAugust. Some of the Kenguri sheep farmers introduced Bellary rams in their flocks, and admixtures of the two sheep breeds were observed. Adequate health care was provided. Animals were vaccinated against haemorrhagic septicaemia, enterotoxaemia and sheep pox. Anthelmintics were used against the endoparasites. Adult mortality in the four breeds ranged from 5-15\%. Flock size of the four breeds varied from small to large. Majority of the Bellary sheep flocks were large to medium sized having average flock size 143 (5 adult males, 106 adult females and 32 young). Most of the Kenguri sheep flocks were medium sized comprising average flock size 87 (4 adult males, 60 adult females and 23 young). Hassan sheep flocks were medium sized consisting average flock size 34 (3 adult males, 23 adult females and 8 young). Flock purity in Bellary, Kenguri and Hassan sheep was approximately 95 percent. Mandya sheep flocks were generally small and in pure form. Average flock size was 16 (1 adult male, 11 adult females and 4 young). At night sheep flocks were housed in a shed thatched with tree branches and crop byproducts with a fenced enclosure made of bushes or locally available material or iron wires. The sheep paddocks were either a part of owner's dwelling or neighbouring to it (Jain et al. 2005a, 2005b, 2006a, 2006b).

\section{Data collection}

Bellary sheep are distributed in Bellary, Davangere districts and the adjoining areas of Haveri and Chitradurga districts. These are of strong built, medium to large sized with coat colour ranging from white through various combinations of white and black to complete black. Kenguri sheep prevails primarily on Koppal and Raichur districts, are large-sized with dark brown (coconut colored) body color. Hassan sheep are small to medium sized having white body colour with light brown or black spots. The breed exists in Hassan district. Mandya sheep are relatively small in size. Coat colour is white with light brown 
face usually extending up to neck. They have compact and low set body with a typical reversed U-shape conformation from the rear, mainly distributed in Mandya district and bordering area of Mysore and Bangalore rural districts of Karnataka (Figure 1). Total number of sheep during the year 2003 within Bellary, Kenguri, Hassan and Mandya distribution areas were 1.516, 0.571, 0.196 and 0.34 million respectively. The corresponding figures in the year 2007 were 2.187, 1.035, 0.201 and 0.382 million (BAHS 2010). While breed-wise population statistics are not in vogue, above figures indicate an increase in total number of sheep in the distribution area of respective breeds during the period 2003-2007. Sampling was carried out from the farmer's flocks in the distribution area on a total of 327 flocks (Bellary, 116; Kenguri, 86; Hassan, 62; Mandya, 63) selected at random. Morphological measurements were taken on 1981 female (f) and male (m) animals (Bellary-576 f, 148 m; Hassan-205 f, 54 m; Kenguri-416 f, $82 \mathrm{~m}$ and Mandya-446 f, $54 \mathrm{~m}$ ). All studied animals were from two teeth to eight teeth of age, which was estimated from their dentition. The six morphometric traits measured were height at withers (HW), body length (BL), chest girth (CG), ear length (EL), tail length (TL) and body weight (BW). The body weights (kilogram) were recorded with a weighing machine. The other traits were measured with a measuring tape (centimeter) after making the animal stand squarely on an even ground.

\section{Statistical analysis}

Descriptive statistics for the morphometric traits were obtained using JMP Genomics 4.1 software of SAS (2009). Means separation was done using Tukey's HSD of the same statistical package at 5\% significance level. The influence of age and flock on the body traits measured was assessed fitting a model which includes the age effect with 4 levels (2-teeth, 4-teeth, 6 teeth and 8 -teeth) and flock effect with different levels in four breeds (Bellary, 116; Kenguri, 86; Hassan, 62; Mandya, $63)$. The sexes were analyzed separately due to differences in sample size and, to the high sexual dimorphism found. Stepwise discriminant procedure was applied using PROC STEPDISC to determine which morphological traits have more discriminant power than others. The relative importance of the morphometric variables

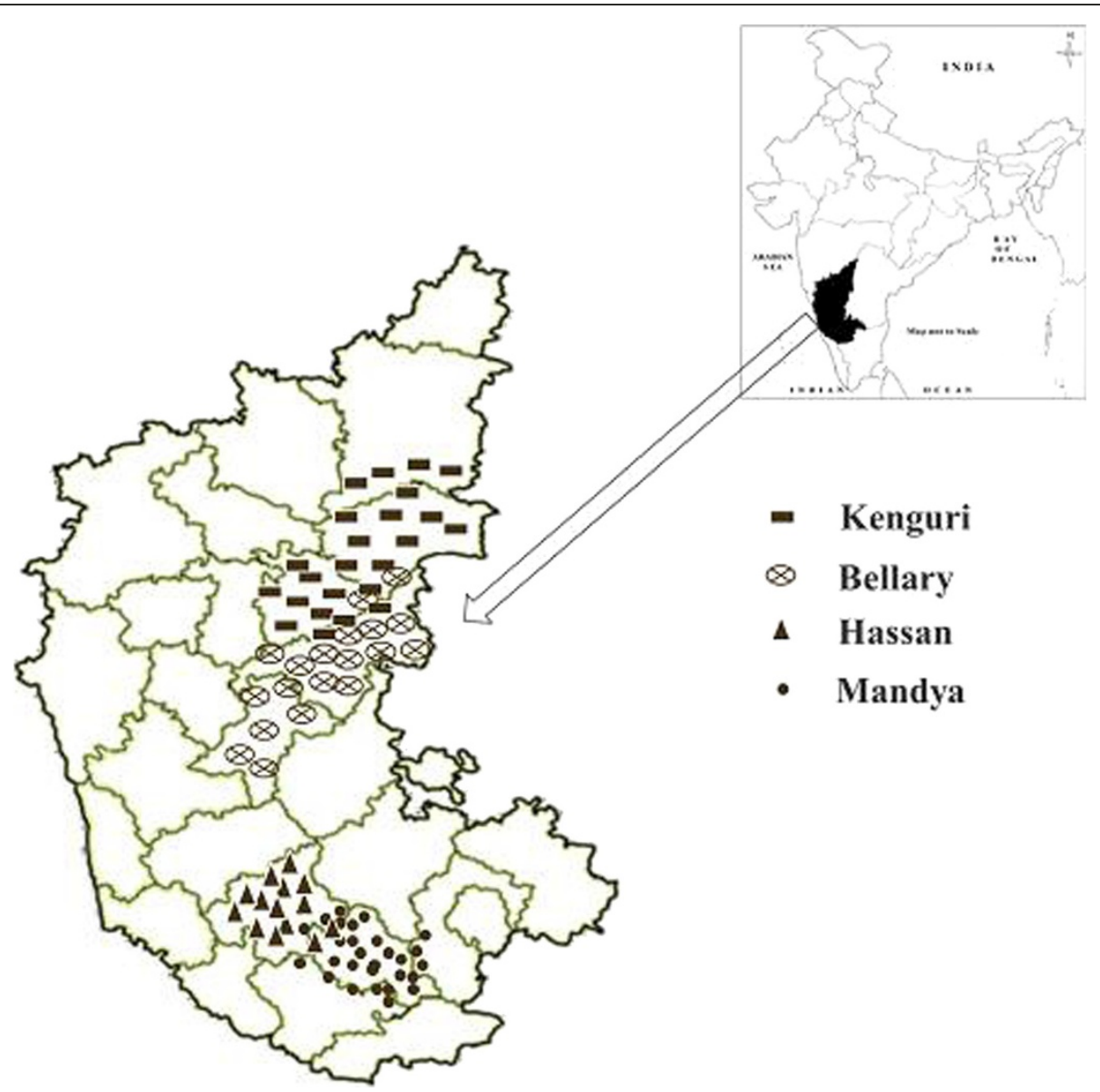

Figure 1 Breeding tract of the four sheep breeds of Karnataka state. 
in discriminating the four breeds of sheep was assessed using the level of significance $(\mathrm{p}<0.05)$ and partial $\mathrm{R}^{2}$ values $\geq 0.01$. The CANDISC procedure was used for calculating the Mahalanobis distances of the morphological traits, and derived canonical functions. The DISCRIM procedure was used to assign each individual sheep to its breed. Mahalanobis distances generated during the canonical discriminant analysis were used to construct a dendrogram using the unweighted pairs group method analysis (UPGMA).

\section{Results}

Means alongwith coefficient of variation for the analyzed morphometric traits of both sexes of four breeds are provided in Table 1. One-way ANOVA determined statistically significant differences between breeds. Amongst the four sheep breeds, Kenguri ewes were the largest and heaviest followed by Bellary, Hassan and Mandya ewes whereas in rams the order was Kenguri followed by Bellary, Mandya and Hassan. The measure of sexual dimorphism $(\mathrm{m} / \mathrm{f})$ has also been included in Table 1 to express these differences between males and females. Kenguri males were $47 \%$ heavier than females, as were values of other traits in all breeds, except for EL which demonstrated no significant differences. The coefficient of variation of all traits in four breeds ranged from 4.06-30.28 percent (females) and 4.7727.29 percent (males). Breed-wise average varied roughly from 9-12.5 percent whereas the overall coefficient of variation of all breeds was 11 percent (males) and 10.4 percent (females). Table 1 also shows the significance of the age of the animal and flock effects on the analyzed traits. Sexual dimorphism was observed in the morphological traits with males having significantly higher $(\mathrm{p}<0.05) \mathrm{BL}, \mathrm{HW}, \mathrm{CG}$, $\mathrm{TL}$ and BW than females. In females, the flock effect was

Table 1 Means, coefficient of variation, and significance of flock and age effects for each of the morphological traits in different sheep breeds

\begin{tabular}{|c|c|c|c|c|c|c|c|c|c|c|}
\hline & \multirow{3}{*}{$\begin{array}{l}\text { Body } \\
\text { Traits }\end{array}$} & \multicolumn{4}{|c|}{ Females } & \multicolumn{4}{|l|}{ Males } & \multirow{3}{*}{$\begin{array}{l}\text { Sexual } \\
\text { dimorphism } \\
(\mathrm{m} / \mathrm{f})\end{array}$} \\
\hline & & \multicolumn{2}{|c|}{ Statistics } & \multicolumn{2}{|c|}{ Fixed effects } & \multicolumn{2}{|c|}{ Statistics } & \multicolumn{2}{|c|}{ Fixed effects } & \\
\hline & & Mean & $\mathrm{CV}$ & Flock & Age & Mean & $\mathrm{CV}$ & Flock & Age & \\
\hline \multirow[t]{6}{*}{ Bellary } & $\mathrm{BL}$ & $65.6^{b}$ & 5.27 & *** & NS & $70.2^{f}$ & 6.73 & $* * *$ & $* * *$ & 1.07 \\
\hline & $\mathrm{HW}$ & $68.9^{b}$ & 4.61 & $* * *$ & NS & $74.5^{f}$ & 5.37 & $* * *$ & $* * *$ & 1.08 \\
\hline & $C G$ & $76.0^{b}$ & 5.43 & $* * *$ & *** & $82.5^{f}$ & 6.25 & $* * *$ & $* * *$ & 1.08 \\
\hline & EL & $13.2^{c}$ & 30.28 & $* * *$ & NS & $13.3^{f}$ & 27.29 & * & NS & 1.00 \\
\hline & $\mathrm{TL}$ & $11.2^{\mathrm{a}}$ & 13.04 & $* * *$ & NS & $12.5^{\mathrm{e}}$ & 12.64 & $* * *$ & NS & 1.12 \\
\hline & BW & $31.8^{b}$ & 16.55 & $* * *$ & $* * *$ & $43.0^{f}$ & 17.54 & $* * *$ & $* * *$ & 1.35 \\
\hline \multirow[t]{6}{*}{ Kenguri } & $\mathrm{BL}$ & $67.3^{\mathrm{a}}$ & 4.48 & $* * *$ & $* * *$ & $74.7^{\mathrm{e}}$ & 5.40 & NS & NS & 1.11 \\
\hline & $\mathrm{HW}$ & $72.6^{a}$ & 4.06 & $* * *$ & NS & $81.5^{\mathrm{e}}$ & 4.77 & NS & NS & 1.12 \\
\hline & $C G$ & $78.4^{\mathrm{a}}$ & 5.22 & $* * *$ & $* * *$ & $89.4^{e}$ & 5.50 & NS & NS & 1.14 \\
\hline & $\mathrm{EL}$ & $15.2^{a}$ & 9.45 & $* * *$ & NS & $15.2^{\mathrm{e}}$ & 8.51 & NS & NS & 0.99 \\
\hline & $\mathrm{TL}$ & $10.1^{b c}$ & 16.26 & $* * *$ & NS & $12.0^{\mathrm{ef}}$ & 16.32 & NS & NS & 1.19 \\
\hline & BW & $35.9^{a}$ & 13.72 & $* * *$ & $* * *$ & $52.6^{e}$ & 14.87 & NS & * & 1.47 \\
\hline \multirow[t]{6}{*}{ Hassan } & $\mathrm{BL}$ & $62.0^{c}$ & 5.07 & $* *$ & ** & $64.3^{h}$ & 7.49 & NS & NS & 1.04 \\
\hline & $\mathrm{HW}$ & $60.8^{c}$ & 5.64 & $* * *$ & NS & $64.4^{9}$ & 7.15 & NS & NS & 1.06 \\
\hline & $C G$ & $71.9^{c}$ & 7.32 & $* * *$ & $* * *$ & $75.2^{h}$ & 7.09 & NS & NS & 1.05 \\
\hline & EL & $14.1^{b}$ & 10.45 & NS & NS & $14.1^{\mathrm{ef}}$ & 9.30 & NS & NS & 0.99 \\
\hline & $\mathrm{TL}$ & $10.3^{b}$ & 13.26 & $* *$ & NS & $11.5^{\mathrm{fg}}$ & 20.03 & NS & NS & 1.11 \\
\hline & BW & $28.3^{c}$ & 17.09 & $* * *$ & $* * *$ & $32.8^{h}$ & 19.22 & NS & NS & 1.16 \\
\hline \multirow[t]{6}{*}{ Mandya } & $\mathrm{BL}$ & $60.5^{d}$ & 6.09 & $* * *$ & $* *$ & $68.3^{9}$ & 5.52 & NS & NS & 1.13 \\
\hline & $\mathrm{HW}$ & $54.3^{d}$ & 8.15 & $* * *$ & ** & $62.3^{h}$ & 7.12 & NS & NS & 1.15 \\
\hline & $C G$ & $69.3^{d}$ & 7.09 & $* * *$ & $* * *$ & $79.1^{\mathrm{g}}$ & 6.86 & $* *$ & NS & 1.14 \\
\hline & $\mathrm{EL}$ & $13.0^{c}$ & 14.12 & $* * *$ & NS & $12.8^{f}$ & 13.73 & * & NS & 0.99 \\
\hline & $\mathrm{TL}$ & $9.9^{c}$ & 11.50 & $* * *$ & $*$ & $10.7^{g}$ & 13.58 & NS & NS & 1.08 \\
\hline & BW & $26.8^{d}$ & 16.32 & $* * *$ & $* * *$ & $37.2^{9}$ & 16.78 & NS & NS & 1.39 \\
\hline
\end{tabular}

BL, body length; HW, height at withers; CG, chest girth; EL, ear length TL, tail length; BW, body weight; CV, coefficient of variation (\%); abcd means (female) and ${ }^{\text {efgh }}$ means (male) in the same column with different superscripts are significantly different ; ${ }^{*}$ Significance level: $p<0.05 ;{ }^{* *}$ Significance level: $p<0.01 ;{ }^{* * *}$ Significance level: $p<0.0001$; Body weights are in kilogram, other traits are in centimetre. 
highly significant $(\mathrm{p}<0.001)$ except EL in Hassan breed while in males it was non-significant except for Bellary breed showing a high homogeneity between flocks. Age effect in females was non-significant for 4, 3, 3 and 1 traits in Bellay, Kenguri, Hassan and Mandya breeds respectively while in males it was non-significant except 4 traits of Bellary breed. The results of the stepwise discriminant analysis are presented in Table 2. All the measured variables were found to be significant ( $\mathrm{p}<0.0001)$ in both sexes. HW had more discriminant power than the others as indicated by their higher $\mathrm{R}^{2}$ and $\mathrm{F}$-values. Therefore, all other variables were removed from the final model (Dossa et al. 2007). In the canonical discriminant analysis, the canonical variable (CAN1) generated was significant $(p<0.0001)$ (Table 3). The Mahalanobis distances between the four sheep breeds are presented in Table 4 which may be termed as short, medium and long. Mahalanobis distance between Kenguri and Mandya can be grouped as long while the distance between Bellary and Kenguri, Bellary and Hassan, and Hassan and Mandya breeds as short. The distance between the Bellary and Mandya and Kenguri and Hassan were intermediate. All pair wise distances were highly significant $(p<0.0001)$, indicating that differences between breeds are important. The largest distance was between Kenguri in the northern Karnataka and Mandya in the far south of the state whereas the shortest distance was between Kenguri and Bellay having flanking breeding tracts. The dendrogram (Figure 2) shows formation of two separate groups, Mandya and Hassan clustering together while Bellary and Kenguri forming another group. Percent classification of individual sheep into four genetic groups is shown in Table 5. In females, most Kenguri sheep (75.72\%) were classified into their source population followed by Mandya (72.65\%). However, while $26.23 \%$ of Mandya ewes were misclassified as Hassan ewes, $16.1 \%$ of Hassan ewes were wrongly assigned as Mandya ewes. Similarly in rams, $38.89 \%$ of Hassan were misclassified as Mandya, 33.33\% of
Table 3 Standardized coefficients or the canonical discriminant function, the canonical correlation and the eigenvalue

\begin{tabular}{lll}
\hline Traits & \multicolumn{2}{l}{ Discriminant variate (CAN1) } \\
\cline { 2 - 3 } & Female & Male \\
\hline HW & 2.28 & 1.95 \\
Adjusted Canonical correlation & 0.899 & 0.860 \\
Approximate standard error & 0.004 & 0.014 \\
Eigenvalue & 4.212 & 2.847 \\
\hline
\end{tabular}

Mandya were wrongly assigned as Hassan rams. Nevertheless, an average of 70 percent females and 67 percent males for the four breeds were correctly assigned into their genetic groups.

\section{Discussion}

Sexual dimorphism was observed in the morphological traits with males having significantly higher $(\mathrm{p}<0.01)$ BL, HW, CG, TL and BW than females. The differences between EL were non-significant. These differences might be due to differences in growth rates, metabolic rates, and growth and reproductive strategies. Considerable variation between breeds was found for morphological traits. Amongst the four sheep breeds, Kenguri ewes were the largest and heaviest followed by Bellary, Hassan and Mandya whereas Kenguri rams were the largest and heaviest followed by Bellary, Mandya and Hassan. It is observed that in females Hassan breed is larger and heavier than Mandya whereas in males the situation is reverse. This could be due to adoption of better management practices in Mandya owing to preferential demand of elite rams for breeding due to its better quality mutton. Mandya sheep possess a compact body with a typical reversed U-shape wedge from the rear and are known for its meaty conformation and excellent meat quality (Acharya 1982; Thangaraju 2009;

Table 2 Stepwise selection summary of traits

\begin{tabular}{|c|c|c|c|c|c|c|c|c|c|}
\hline Sex & Step & Trait entered & Partial $\mathrm{R}^{2}$ & F-value & $p>F$ & Wilk's lambda & $\mathrm{P}<$ lambda & $\begin{array}{l}\text { Average squared } \\
\text { canonical correlation }\end{array}$ & $p>A S C C$ \\
\hline \multirow[t]{6}{*}{ Female } & 1 & HW & 0.808 & 2301.53 & $<0.0001$ & 0.19183 & $<0.0001$ & 0.269 & $<0.0001$ \\
\hline & 2 & $\mathrm{TL}$ & 0.116 & 72.19 & $<0.0001$ & 0.16943 & $<0.0001$ & 0.306 & $<0.0001$ \\
\hline & 3 & BW & 0.094 & 56.80 & $<0.0001$ & 0.15346 & $<0.0001$ & 0.328 & $<0.0001$ \\
\hline & 4 & EL & 0.077 & 45.63 & $<0.0001$ & 0.14161 & $<0.0001$ & 0.348 & $<0.0001$ \\
\hline & 5 & $C G$ & 0.031 & 17.19 & $<0.0001$ & 0.13728 & $<0.0001$ & 0.356 & $<0.0001$ \\
\hline & 6 & $B L$ & 0.015 & 8.66 & $<0.0001$ & 0.13513 & $<0.0001$ & 0.359 & $<0.0001$ \\
\hline \multirow[t]{5}{*}{ Male } & 1 & HW & 0.740 & 317.01 & $<0.0001$ & 0.25991 & $<0.0001$ & 0.246 & $<0.0001$ \\
\hline & 2 & $B L$ & 0.223 & 31.87 & $<0.0001$ & 0.20193 & $<0.0001$ & 0.305 & $<0.0001$ \\
\hline & 3 & $\mathrm{TL}$ & 0.086 & 10.47 & $<0.0001$ & 0.18448 & $<0.0001$ & 0.331 & $<0.0001$ \\
\hline & 4 & $C G$ & 0.077 & 9.29 & $<0.0001$ & 0.17015 & $<0.0001$ & 0.351 & $<0.0001$ \\
\hline & 5 & EL & 0.066 & 7.77 & $<0.0001$ & 0.15892 & $<0.0001$ & 0.372 & $<0.0001$ \\
\hline
\end{tabular}


Table 4 Mahalanobis distance between the four sheep breeds*

\begin{tabular}{lllll}
\hline Breed & Bellary & Kenguri & Hassan & Mandya \\
\hline Bellary & $\mathbf{0}$ & 1.08 & 5.20 & 16.84 \\
Kenguri & 2.85 & $\mathbf{0}$ & 11.01 & 26.43 \\
Hassan & 5.88 & 16.92 & $\mathbf{0}$ & 3.32 \\
Mandya & 8.66 & 21.44 & 0.27 & $\mathbf{0}$ \\
\hline
\end{tabular}

*Above diagonal values are of females and below diagonal are of males.

Jain et al. 2005b). The mean values (Table 1) would allow for the defining of the adult morphological standard of the four breeds from both the mean point of view as well as variability. The coefficient of variation of all traits in four breeds ranged from 4.06-30.28 percent with only EL, TL and BW higher than 10 percent which corresponds with a mean homogeneity within the breed (Herrera 2007). The overall coefficient of variation of all breeds was slightly higher in males $(11.0 \%)$ than females (10.4\%) indicating the overall lower heterogeneity of females than among males when viewed globally. The flock effect was highly significant $(\mathrm{p}<0.001)$ in females of all breeds while it was non-significant in males of all breeds except Bellary. Sample size could be the possible reason for this exception. The number of males sampled in Bellary was large (148) as compared to other breeds (Kenguri: 82; Hassan: 54; Mandya: 54). In view of significant flock effect females appear different between flocks; the overall heterogeneity of females is even lower than among males when viewed globally. The age had highly significant effect $(\mathrm{p}<0.001)$ only for two $(\mathrm{CG}$ and $\mathrm{BW})$ traits, showing a high heterogeneity among females of different flocks while in males it resulted non-significant effects except for Bellary breed showing a high homogeneity between flocks, an indication that possible influencing factors could be a smaller sampling of males and differential treatment that males receive. Legaz et al. 2011 demonstrated similar findings in Assaf sheep and reasoned that fewer males could be an influencing factor in the signification.

The best discriminant function model used in this study included only one morphological measure (HW)
Table 5 Percent (\%) of individual sheep classified into four genetic groups

\begin{tabular}{llllll}
\hline Sex & Breed & Bellary & Kenguri & Hassan & Mandya \\
\hline Female & Bellary & 61.81 & 29.34 & 8.85 & 0 \\
& Kenguri & 24.04 & 75.72 & 0.24 & 0 \\
& Hassan & 13.66 & 0.49 & 69.75 & 16.10 \\
& Mandya & 1.12 & 0 & 26.23 & 72.65 \\
& Error level & 0.38 & 0.24 & 0.30 & 0.27 \\
& Priors & 0.25 & 0.25 & 0.25 & 0.25 \\
\multirow{4}{*}{ Male } & Bellary & 67.57 & 20.27 & 12.16 & 0 \\
& Kenguri & 13.41 & 86.59 & 0 & 0 \\
& Hassan & 5.56 & 1.85 & 53.70 & 38.89 \\
& Mandya & 5.56 & 0 & 33.33 & 61.11 \\
& Error level & 0.32 & 0.13 & 0.46 & 0.39 \\
& Priors & 0.25 & 0.25 & 0.25 & 0.25 \\
\hline
\end{tabular}

out of the six pre-selected. This demonstrates that taking measurements on this trait could be sufficient in differentiating between these four sheep breeds than acquiring numerous other measurements on morphometric traits. Some of the discriminating variables obtained in the present study are similar to earlier findings (Herrera et al. 1996; Dossa et al. 2007; Yakubu et al. 2011) in the morphostructural differentiation of sheep and goat breeds/populations.

The Mahalanobis distances differed between sexes and breeds. The highest distance between Kenguri and Mandya possibly reflect differences in body size. Generally, such phenotypic divergence between breeds/populations might be partly associated with the differences in management practices, agro-climatic conditions and biophysical resources. Relative breeding objectives depending upon the utility of the breed may also act as important factor. Mandya sheep are relatively smaller in size having compact body as compared to Kenguri and Bellary sheep. Therefore, differences in Mahalanobis distances between different populations and sexes are highly likely to exist. Larger the differences in body measures, larger are the distances between the breeds/populations. Similar results were reported in sheep, goats and horses (Dossa et al. 2007; Yakubu et al.

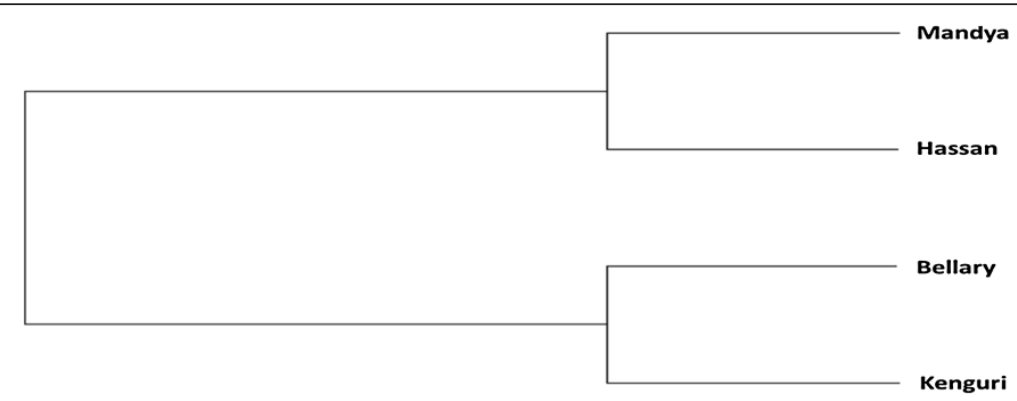

Figure 2 UPGMA tree based on pair-wise Mahalanobis distances of four sheep breeds. 
2011; Yakubu and Ibrahim Isa 2011; Kefena et al. 2012). Diversity in morphometric traits between breeds could be due to genetic differences as well as environmental factors and may reflect the level of adaptation of these breeds to specific agro-climatic conditions of their distribution areas. The genetic distance theoretically describes the differences between breeds. Phenotypic comparison based on morphological characters can provide to some extent a reasonable representation of genetic differences among populations (Dossa et al. 2007). Phenotypic differences are maintained in part by the reduction of gene flow among populations separated by large distances (Yakubu and Ibrahim Isa 2011). The results indicate that adaptive divergence in morphological traits was higher between Kenguri and Mandya, Bellary and Mandya, and Kenguri and Hassan sheep and lower between Kenguri and Bellary, Hassan and Mandya, and Hassan and Bellary sheep. The higher divergence among breeds that commensurate geographical distance of their respective habitat may be due to reproductive isolation by distance. However, the correlation of morphological divergence with quantitative differences in economically important traits like growth rate, body weight at different ages and carcass characteristics of these breeds may help to formulate strategy for planned breeding in future. The lower divergence may be due to the genetic exchange that has taken place overtime between the breeds owing to their management practices, geographical proximity and intermixing. Kumar et al. 2006; Singh et al. 2007; Yadav et al. 2009, 2011 have reported genetic/breed dilution in Indian sheep due to intermixing. Similar results on adaptive divergence in morphological characters during the morphometric differentiation of sheep were reported on Ethiopian sheep (Gizaw et al. 2007) and Nigerian sheep (Yakubu and Ibrahim Isa 2011).

The discriminant analysis revealed that an average of 70 percent females and 67 percent males correct classification of the sampled sheep of the four breeds can be achieved using HW variable. This indicates the heterogeneity of the sheep breeds. The misclassification percentages were $24-38 \%$ (females) and 13-46\% (males). The reason that could be adduced for these misclassifications is intermingling between the four sheep breeds. As evident from Figure 1 and Figure 2, the four breeds group into two clusters viz. northern part of the state (Kenguri and Bellary) and southern part (Hassan and Mandya). The genetic admixture could have been brought about mainly by the activities of pastoralists who moved from one place to another with their flocks in search of pasture and water. Such transhumance has been cited as a dynamic factor of gene exchange (Draganescu 1997), which is also supported by the management practices of these breeds (Jain et al. 2005a, 2005b, 2006a, 2006b). Several other studies have also reported genetic/breed dilution in Indian sheep due to intermixing (Kumar et al. 2006; Singh et al. 2007; Yadav et al. 2009, 2011). Close/overlapping body measures of animals of different breeds/groups could also be a factor to the misclassification of animals. Nevertheless, the computed high degree of correct classification of sheep in their respective genetic source group (breed) confirmed the high discriminating power of the morphological measurement (HW). The use of multivariate discriminant analyses therefore could be successfully used in morphometric differentiation of the four sheep breeds. The findings are in consonance with earlier reports on the use of discriminant analysis to classify animals of different genetic groups or ecotypes (Zaitoun et al. 2005; Dossa et al. 2007; Traoré et al. 2008; Yakubu et al. 2011). Nevertheless, the method may have a limitation. It is possible that if the phenotypic distributions of a trait are overlapping between two populations, it will not be able to classify such individuals correctly in their source group. Two individuals may be very similar with respect to body weight, body length or tail length, but even then they could be genetically quite distant. Molecular marker information is needed to make the distinction clear. Hence, further characterization using comparative genetic analyses will consolidate information arising from morphological differentiation. Such phenotypic and genetic data when logically combined into a single database could be critical for decisions regarding indigenous sheep breeds' exploitation and conservation (Kunene et al. 2009).

\section{Conclusions}

The study establishes the structure and the degree of variability between the four breeds. The application of univariate and multivariate statistical methods enabled us to discriminate between the sheep breed using morphometric traits. HW was found as the most discriminating trait in separating the breeds. Flock and age effects established high heterogeneity among females of different flocks whereas in males these effects showed homogeneity between flocks except for Bellary breed. High Mahalanobis distance coupled with zero percent misclassification between Kenguri and Mandya indicated negligible genetic exchange between these breeds. The low Mahalanobis distance between Kenguri and Bellary, Hassan and Mandya, and Hassan and Bellary at the morphological level could be attributed to the genetic exchange that has taken place between these sheep breeds. However, in overlapping morphometric traits the method has a limitation which can be corroborated by genetic characterization using genetic markers. Nevertheless, the classical discriminant function analysis has successfully classified the four breeds in distinct groups. 


\section{Competing interests}

The authors declare that they have no competing interests.

\section{Authors' contributions}

DKY carried out the analysis and wrote the manuscript; AJ, VSK, and DKS planned the survey and collected the data; MGG and TA assisted in planning and coordination of the survey. The authors read and approved the final manuscript.

\section{Acknowledgments}

The authors are thankful to Director, NBAGR, Karnal for providing the facilities for carrying out the study. Director, Research, UAS, Dharwad is duly acknowledged for permitting Dr. Kulkarni for the study on Kenguri and Bellary sheep. Officers of the Department of Animal Husbandry and Veterinary Sciences, Karnataka are acknowledged for their help and cooperation during the course of study. This research could not have succeeded without the help and support of many farmers who allowed the measurements of their sheep. All farmers who spared their valuable time as well as animals for study are duly acknowledged.

\section{Author details}

${ }^{1}$ National Bureau of Animal Genetic Resources, G. T. Road, Baldi By-Pass, Karnal 132 001, Haryana, India. ${ }^{2}$ University of Agricultural Sciences, Dharwad 580 005, Karnataka, India. ${ }^{3}$ KVAFSU, Veterinary College, Bangalore 560024 , Karnataka, India. ${ }^{4}$ Department of Animal Husbandry and Veterinary Services, Bangalore 560 001, Karnataka, India.

\section{Received: 30 October 2012 Accepted: 24 January 2013}

Published: 29 January 2013

\section{References}

Acharya RM (1982) Sheep and goat breeds of India. FAO Animal Production and Health Paper, 30. FAO, Rome, Italy

BAHS-Basic Animal Husbandry Statistics (2010) Department of Animal Husbandry, Dairying \& Fisheries, Ministry of Agriculture, Government of India. Krishi Bhavan, New Delhi

Bhatia S, Arora R (2005) Biodiversity and conservation of Indian sheep genetic resources an overview. Asian-Aust J Anim Sci 18:1387-1402

Bohra SDJ, Jain A, Sharma SC (1993) Kheri a new type of sheep in Rajasthan (India). Wool \& Woollens of India, Jan-Mar, pp 23-24

Dossa LH, Wollny C, Gauly M (2007) Spatial variation in goat populations from Benin as revealed by multivariate analysis of morphological traits. Small Rumin Res 73:150-159

Draganescu C (1997) Transhumance and the relationship between sheep breeds in Central Eastern Europe and the Mediterranean area. In: Proceedings of International Symposium on Mediterranean animal germplasm and future human challenge, Benevento, Italy 85., pp 101-106

Duchev Z, Groeneveld E (2006) Improving the monitoring of animal genetic resources on National and International level. Archiv Anim Breed 49:532-544

FAO (2000) World Watch List for domestic animal diversity, 3rd edn. Information Division, FAO, Rome

FAOSTAT (2010) FAOSTAT Agriculture Data. Food and Agriculture Organization Statistics, Rome, Italy

Gizaw S, Van Arendonk JAM, Komen H, Windig JJ, Hanotte O (2007) Population structure, genetic variation and morphological diversity in indigenous sheep of Ethiopia. Anim Gen 38:621-628

Herrera M, Rodero E, Gutierrez MJ, Pena F, Rodero JM (1996) Application of multifactorial discriminant analysis in the morphostructural differentiation of Andalusian caprine breeds. Small Rumin Res 22:39-47

Herrera M (2007) Metodología de Caracterización zootecnológica. In: La Ganadería Andaluza en el siglo XXI, vol. I., pp 435-448

Jain A, Kulkarni VS, Govindaiah MG, Sadana DK, Aswathnarayan T, Pandey AK, Kumar D, Sharma R, Singh G (2005a) Sheep Genetic Resources of India: Bellary. National Bureau of Animal Genetic Resources, Karnal, India

Jain A, Sadana DK, Govindaiah MG, Kulkarni VS, Aswathnarayan T, Pandey AK, Kumar D, Sharma R, Singh G (2005b) Sheep Genetic Resources of India. Mandya, National Bureau of Animal Genetic Resources, Karnal, India

Jain A, Kulkarni VS, Govindaiah MG, Sadana DK, Aswathnarayan T, Pandey AK, Kumar D, Sharma R, Ahlawat SPS (2006a) Sheep Genetic Resources of India. Kenguri, National Bureau of Animal Genetic Resources, Karnal, India
Jain A, Govindaiah MG, Sadana DK, Kulkarni VS, Aswathnarayan T, Pandey AK, Sharma R, Kumar D, Ahlawat SPS (2006b) Sheep Genetic Resources of India. Hassan, National Bureau of Animal Genetic Resources, Karnal, India

Jain A, Singh G, Yadav DK (2009) Chokla - an endangered sheep genetic resource. Ind J Anim Sci 79(10):1071-1072

Kefena E, Dessie T, Han JL, Kurtu MY, Rosenbom S, Beja-Pereira A (2012) Morphological diversities and ecozones of Ethiopian horse populations. Anim Gen Resour Info 50:1-12

Kumar D, Singh G, Jain A (2006) Characterization and evaluation of Muzaffarnagri sheep. Ind J Small Rumin 12(1):48-55

Kunene NW, Bezuidenhout CC, Nsahlai IV (2009) Genetic and phenotypic diversity in Zulu sheep populations: implications for population. Small Rumin Res 84:100-107

Lanari MR, Taddeo H, Domingo E, Pérez Centeno M, Gallo L (2003) Phenotypic differentiation of Criollo goat population in Patagonia (Argentina). Archiv Anim Breed 46(4):347-356

Legaz E, Cervantes I, Pérez-Cabal MA, de la Fuente LF, Mártinez R, Goyache F, Gutiérrez JP (2011) Multivariate characterisation of morphological traits in Assaf (Assaf.E) sheep. Small Rumin Res 100:122-130

Parés i Casanova PM (2009) Zoometría. Valoraciónmorfológica de los animals domésticos. Minist. Medio Ambiente Medio Rural Mar 6:171-196 (in Spanish)

Sahana G, Gupta SC, Nivsarkar AE (2001) Garole: The prolific sheep of India. Anim Gen Resour Info 31:55-63

SAS (2009) SAS/STAT User's Guide. Release 9.2. SAS Institute Inc, Cary, NC, USA

Simon DL (1999) European approaches to conservation of farm animal genetic resources. Anim Gen Resour Info 25:79-99

Singh G, Jain A, Yadav DK (2007) Evaluation of Nali sheep under field conditions. Ind J Anim Sci 77(11):1158-1160

Thangaraju P (2009) Status of animal genetic resources (AnGR) in South India. In: Proceedings of National Symposium on Livestock Biodiversity Conservation \& Utilization: Lessons from Past and Future Perspectives, February 12-13. NBAGR, Karnal, Haryana, India, p 36

Traoré A, Tamboura HH, Kabore A, Royo LJ, Fernández I, Álvarez I, Sangare M, Bouchel D, Poivey JP, Francois D, Toguyeni A, Sawadogo L, Goyache F (2008) Multivariate characterization of morphological traits in Burkina Faso sheep. Small Rumin Res 80:62-67

Yadav DK, Singh G, Jain A, Singh S, Paul AK (2009) Fitting of growth models and evaluation of Marwari sheep under field conditions. Ind J Anim Sci 79 (12):1242-1244

Yadav DK, Arora R, Bhatia S, Singh G (2011) Morphological characterization, production and reproduction status of Munjal -A threatened sheep population of North-West India. Ind J Anim Sci 81(9):943-945

Yadav DK, Jain A, Singh G, Arora R, Bhatia S (2012) A comparison of body biometry traits of Munjal and Muzaffarnagri sheep under field conditions. Ind J Anim Sci 82(2):216-219

Yakubu A, Salako AE, Imumorin IG (2011) Comparative multivariate analysis of biometric traits of West African Dwarf and Red Sokoto goats. Trop Anim Health Prod 43:561-566

Yakubu A, Ibrahim Isa A (2011) Multivariate analysis of Morphostructural characteristics in Nigerian Indigenous sheep. Ital J Anim Sci 10(e17):83-86

Zaitoun IS, Tabbaa MJ, Bdour S (2005) Differentiation of native goat breeds of Jordan on the basis of morphostructural characteristics. Small Rumin Res $56: 173-182$

doi:10.1186/2193-1801-2-29

Cite this article as: Yadav et al:: Classification of four ovine breeds of southern peninsular zone of India: Morphometric study using classical discriminant function analysis. SpringerPlus 2013 2:29. 